\title{
Brain Training with Fractal Optical Stimulation to Improve the Performance of Table Tennis Athletes
}

\author{
Zueva Marina $\mathrm{V}^{1 *}$, Makarenko Nadezhda ${ }^{2}$, Belyaev Fedor $\mathrm{P}^{2}$, Karankevich Alexander $\mathrm{I}^{3}$ and Belitskaya Lyubov \\ $\mathrm{A}^{2}$
}

${ }^{1}$ Moscow Helmholtz Research Institute of Eye Diseases, Russian Federation

${ }^{2}$ Russian State University of Physical Education, Sport, Youth and Tourism, Russian Federation

${ }^{3}$ Bauman Moscow State Technical University, Russian Federation

Submission: July 28, 2018; Published: August 08, 2018

*Corresponding author: Zueva Marina V, Moscow Helmholtz Research Institute of Eye Diseases, Russian Federation, Email: visionlab@yandex.ru

\section{Abstract}

We hypothesized that in healthy individuals the low-intensity stimulation with fractal optical stimuli, whose structure are close to the activity of a healthy brain may be helpful method of brain training and promote favorable psychophysiological changes through the mechanism of brainwave entrainment. The purpose of this study was to evaluate the effect of short-term training of the brain using fractal optical stimulation on the performance of table tennis athletes. 12 students with a basic level of training in table tennis were tested before and after a 10-minute break. In the main group, in the time of break, the training was performed using ten minutes fractal photo-stimulation. The fractal dimension of the complex-structured signal specified by the computer program was 1.4. Fractal structure of stimuli has been created based on Weier strass functions. Psychophysiological tests included assessment of a simple visual motor reaction, contact tremorometry, investigation of the critical flicker frequency, pulsometry, and motor tests with targets.

As a result of this pilot study, we first presented the evidence of the positive influence of low-intensity stimulation with fractal optical stimuli on psychophysiological parameters characterizing the physical and mental performance of the table tennis athletes. The short-term training of the brain by fractal photo-stimulation improves the psychophysiological parameters characterizing the physical and cognitive performance of table tennis players.

Keywords: Brain training; Complex-structured optical signals; Fractals; Performance; Table tennis

Abbreviations: ADT: The Average Duration of the Touch (in tremorometry); AFT: The Average Frequency of Touch (in tremorometry); CFF: Critical Flicker Frequency (the critical frequency of flicker fusion); FD: Fractal Dimension; MB: The Method of Multi-ball; SVMR: Simple Visual Motor Reaction; SD: Standard Deviation; M: Arithmetic Mean;

\section{Introduction}

Table tennis, as a dynamic game with a moving emotional background, makes high demands on the physical and mental qualities of athletes. Temperament, reaction speed, attention and visual perception distinguish high-class players [1]. The resulting emotional disturbances can cause a decrease in psychophysiological reliability, adversely affecting the athlete's technical and tactical performance [2,3]. The success of professional tennis players largely depends on the psychological state before and during the competition, the ability to instantly relax and strain at certain moments, adequately assess their strengths. It is known that among the best tennis players with an equal physical condition the winners are those who will be able to maintain their cognitive functions at the highest level under conditions of prolonged of physical and mental stress, who will not have sudden changes in the balance between the processes of inhibition and excitation in the central nervous system [4]. An important observation of sports psychologists is that at the highest level of sporting achievements the gap between victory and defeat is determined by the mental ability of the athlete $[4,5]$.

To combat anxiety, a common problem for all athletes, methods are needed that help to accelerate recovery processes (such as relaxation techniques and breathing exercises), but at the same time, the athletes remain concentrated, ready for instant decision making. It is necessary to further search for methods for correcting psycho-emotional state, maintaining or increasing cognitive abilities, especially in a state of fatigue and overexertion, increasing the speed of recovery of athletes. In the search for new technologies that can influence the brain and improve its functions, the possibilities of audio and visual stimulation are being studied today. Effects of rhythmic sensory stimulation are based on the "Frequency Follow Response" phenomenon also called as a "Brainwave Entrainment" related with a high ability of the brain to synchronize its dominant 
oscillatory activity with the rhythm of external low-frequency influences [6]. Through physical stimuli (sound or light), one can act on brain activity, memory and other cognitive functions of a person [7].

Rhythmic stimulation is so far driven by stimuli of a rigidly set frequency of sound and light signals, which, however, does not allow reconstructing a complex set of physiological functions $[8,9]$. Healthy physiological processes are known to have fractal dynamics, which is lost in aging and pathology $[10,11]$. Stress has an impact on the activity of the brain [12] and can induce alterations in learning and memory processes [13-15]. Stress alters long-range correlations (fractal behavior) of physiological systems. In persons with emotional disorders, physiological systems were shown to be characterized by lowered complexity and show less flexibility to adjust to changing conditions [16]. In 2013, we for the first time drew attention to the importance of the fractal structure of light flashes in the electrophysiological diagnosis and treatment of neurodegenerative diseases of the retina and the brain [17]. In subsequent publications, we substantiated the advisability of studying the effects of fractal stimulation as a new approach to neurorehabilitation in traumas and brain diseases, and as a method of brain training in healthy individuals who need to restore their functions quickly $[8,9]$.

The latter would be especially important for athletes to maintain a psycho-emotional state. Given the current scientific understanding of the importance of fractal stimulation for restoring the dynamics of brain activity, it is essential to study the influence of fractal stimuli for enhancing and restoring the physical and mental performance of table tennis athletes. We assume that in healthy individuals, fractal photo-stimulation by low-intensity complex-structured flickering, whose parameters are close to the activity of a healthy brain, through the mechanism of brainwave synchronization will play the role of cognitive brain training and promote favorable psychophysiological changes in athletes. The purpose of our study was to evaluate the effect of short-term training using fractal optical stimulation on the performance of table tennis athletes.

\section{Materials and Methods}

12 students of Russian State University of Physical Education, Sport, Youth and Tourism (RSU PESYT) having a basic level of training in table tennis took part in the test. Participants were divided into the control and the main group by six students. In each group, testing was conducted twice: before and after a 10-minute break. In the main group, in the time of the break, the training of the brain was carried out using ten minutes fractal photo-stimulation. In the control group, instead of optical stimulation, a quiet rest was used before further testing. Then, the physiological shifts in the control and main groups were compared. Low-intensity fractal stimulation has been performing using the device, in which LED lamps are mounted in the body of the virtual reality glasses. The photo-stimulator produces a non-uniform scattered light field for both eyes with nonlinearly generated light signals (the maximal intensity 10-12 Lx at the cornea). The fractal dimension (FD) of the complex-structured signal specified by the computer program was 1.4. Fractal structure of signals is created based on Weierstrass functions. The study has been carried out following the principles of the Declaration of Helsinki, the Local Ethics Committee of the RSU PESYT and with the informed consent of the students.

In work, psychophysiological tests were used, including assessment of a simple visual motor reaction (SVMR), contact tremorometry, investigation of the critical frequency of flicker fusion (CFF) (critical flicker frequency) and pulsometry, and motor tests (test with targets). Psychophysiological tests were conducted with the help of a particular program "NSPsychoTest." In the test with the targets, the method of Multiball (MB) was used. With this method, 20 balls were throwing into a specific zone (right far corner-test No. 1 and left far corner-test No. 2). In the first test, when the balls are serviced to the right-hand corner, the tennis player had to execute the forehand stroke diagonally to the given target, located in the right-hand corner. In the second test, when the balls were being fed to the left corner, the subject had to execute the backhand stroke diagonally to the given target, located in the left-hand corner. The size of the target is $20 * 20 \mathrm{~cm}$. Before the testing began, an attempt was made in the form of 2 trial strokes on the thrown ball. The number of successful strokes in the target was estimated. Strokes were recorded using carbon copy. Statistical analysis was performed using STATISTICA (TIBCO Software Inc., Version 13.3). The indices for all the tests before and after the break for rest or fractal stimulation are presented in the Tables 1-4.

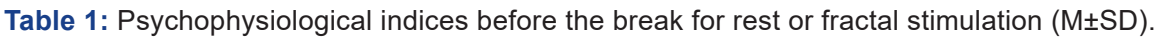

\begin{tabular}{|c|c|c|c|c|c|c|c|c|}
\hline \multirow{3}{*}{ Psychophysiological tests } & \multicolumn{4}{|c|}{ Groups } & \multirow{2}{*}{\multicolumn{2}{|c|}{ Difference }} & \multirow{3}{*}{$\begin{array}{c}\text { Student's } \\
\text { t-test }\end{array}$} & \multirow[t]{3}{*}{$\mathbf{P}$} \\
\hline & \multicolumn{2}{|c|}{ Control $(n=6)$} & \multicolumn{2}{|c|}{ Main $(n=6)$} & & & & \\
\hline & $\mathbf{M}$ & SD & $\mathbf{M}$ & SD & abs. units & $\%$ & & \\
\hline SVMR & 205,7 & 22,9 & 211,3 & 13,1 & 5,6 & 2,65 & 0,5 & $\mathrm{p} \leq 0.05$ \\
\hline AFT & 2,98 & 1,05 & 2,60 & 1,05 & 0,38 & 12,75 & 0,6 & $\mathrm{p} \leq 0.05$ \\
\hline ADT & 3,15 & 0,65 & 2,64 & 1,21 & 0,51 & 16,19 & 0,9 & $\mathrm{p} \leq 0.05$ \\
\hline CFF right eye & 25,5 & 4,49 & 26,08 & 4,85 & 0,58 & 2,22 & 0,2 & $\mathrm{p} \leq 0.05$ \\
\hline CFF left eye & 23,01 & 6,14 & 30 & 3,07 & 6,99 & 23,3 & 2,5 & $\mathrm{p} \leq 0.05$ \\
\hline Heart rate & 84,8 & 10,6 & 83,3 & 12,2 & 1,5 & 1,77 & 0,2 & $\mathrm{p}>0,05$ \\
\hline
\end{tabular}


Table 2: Psychophysiological indices after the break for rest or fractal stimulation (M \pm SD).

\begin{tabular}{|c|c|c|c|c|c|c|c|c|}
\hline \multirow{3}{*}{$\begin{array}{c}\text { Psychophysiological } \\
\text { tests }\end{array}$} & \multicolumn{4}{|c|}{ Groups } & \multirow{2}{*}{\multicolumn{2}{|c|}{ Difference }} & \multirow{3}{*}{$\begin{array}{l}\text { Student's } \\
\text { t-test }\end{array}$} & \multirow{3}{*}{$\mathbf{P}$} \\
\hline & \multicolumn{2}{|c|}{ Control $(n=6)$} & \multicolumn{2}{|c|}{ Main $(n=6)$} & & & & \\
\hline & $\mathbf{M}$ & SD & $\mathbf{M}$ & SD & abs. units & $\%$ & & \\
\hline SVMR & 206,6 & 19,15 & 197,7 & 5,5 & 8,9 & 4,3 & 1,1 & $\mathrm{p} \leq 0.05$ \\
\hline $\mathrm{AFT}$ & 2,74 & 0,84 & 2,02 & 0,76 & 0,72 & 26,28 & 1,6 & $\mathrm{p} \leq 0.05$ \\
\hline $\mathrm{ADT}$ & 2,91 & 0,81 & 1,97 & 1,04 & 0,94 & 32,3 & 1,7 & $\mathrm{p} \leq 0.05$ \\
\hline CFF right eye & 26,7 & 3.45 & 30,6 & 1,95 & 3,9 & 12,7 & 2,4 & $\mathrm{p} \leq 0.05$ \\
\hline CFF left eye & 23,43 & 5.7 & 33,06 & 2,85 & 9,63 & 29,12 & 3,7 & $\mathrm{p} \leq 0.05$ \\
\hline Heart rate & 72 & 3 & 71 & 3,7 & 1 & 1,38 & 0,5 & $>0,05$ \\
\hline
\end{tabular}

Table 3: Indices of the motor tests with targets before the break for rest or fractal stimulation (M $\pm S D$ ).

\begin{tabular}{|c|c|c|c|c|c|c|c|c|}
\hline \multirow{3}{*}{ Motor tests } & \multicolumn{4}{|c|}{ Groups } & & & \multirow{3}{*}{$\begin{array}{c}\text { Student's } \\
\text { t-test }\end{array}$} & \multirow{3}{*}{$\mathbf{P}$} \\
\hline & $\begin{array}{l}\text { Control } \\
(n=6)\end{array}$ & & Main $(n=6)$ & & \multicolumn{2}{|c|}{ Difference } & & \\
\hline & $\mathbf{M}$ & SD & $\mathbf{M}$ & SD & abs. units & $\%$ & & \\
\hline $\begin{array}{l}\text { The test with } \\
\text { target } 1\end{array}$ & 4,83 & 0,75 & 6,16 & 1,9 & 1,33 & 22 & 1,6 & $\mathrm{p} \leq 0.05$ \\
\hline $\begin{array}{l}\text { The test with } \\
\text { target } 2\end{array}$ & 4,66 & 1,97 & 7,83 & 1,47 & 3,17 & 40,4 & 3,2 & $\mathrm{p} \leq 0.05$ \\
\hline
\end{tabular}

Table 4: Indices of the motor tests with targets after the break for rest or fractal stimulation $(M \pm S D)$.

\begin{tabular}{|c|c|c|c|c|c|c|c|c|}
\hline \multirow{3}{*}{ Motor tests } & \multicolumn{4}{|c|}{ Groups } & \multirow{2}{*}{\multicolumn{2}{|c|}{ Difference }} & \multirow{3}{*}{$\begin{array}{c}\text { Student's } \\
\text { t-test }\end{array}$} & \multirow{3}{*}{$\mathbf{P}$} \\
\hline & \multicolumn{2}{|c|}{ Control $(n=6)$} & \multicolumn{2}{|c|}{ Main $(n=6)$} & & & & \\
\hline & M & SD & $\mathbf{M}$ & SD & abs. units & $\%$ & & \\
\hline $\begin{array}{l}\text { The test with } \\
\text { target } 1\end{array}$ & 4,5 & 2,07 & 6,16 & 1,17 & 1,66 & 27 & 1,7 & $\mathrm{p} \leq 0.05$ \\
\hline $\begin{array}{l}\text { The test with } \\
\text { target } 2\end{array}$ & 5,16 & 1,9 & 9 & 1,55 & 3,84 & 42,7 & 3,8 & $\mathrm{p} \leq 0.05$ \\
\hline
\end{tabular}

Results

\section{Test for a Simple Visual-Motor Reaction}

In the main group, the use of the device led to a significant $(p \leq 0.05)$ improvement in the SVMR by $6.48 \%$. In the control group, on the contrary, the reaction rate decreased (correspondently, the time of reaction increased) by $0.43 \%$ suggesting that ordinary rest for 10 minutes is not enough for a complete recovery of reaction time. The phenomenon of the significant reduction of the SVMR after the one séance of fractal photo-stimulation may be related to an improvement of the mobility of nervous processes.

\section{Critical Frequency of Flicker Fusion}

CFF was evaluated separately for both eyes. In the main group, the increase in this indicator for the right eye was more significant $(\mathrm{p} \leq 0.05)$ than in the control group. CFF averaged $14.77 \%$ after the fractal stimulation compared with $4.5 \%$ after the regular rest (Table 1). The increase in the parameters for the left eye of athletes in the main group was also better than in the control group $(\mathrm{p} \leq 0.05)$ and amounted to $9.25 \%$ and $1.8 \%$ accordingly. Thus, in the main group, the lability of visual pathways restored after exercise stress more efficiently if the brain's training with fractal optical stimulation is used than in conventional rest for both eyes. This positive effect of fractal stimulation was more pronounced for the left eye.

\section{Contact Tremorometry}

Two parameters of contact tremorometry were estimated - the average frequency of touch (AFT, Hz) and the average duration of the touch (ADT, s). The AFT value in the main group showed a significant $(p \leq 0.05)$ decrease by $22.3 \%$ after the fractal stimulation. In the control group, it decreased by $8.05 \%$ after the normal rest. The ADT parameter was reliably decreased by $25.37 \%(\mathrm{p} \leq 0.05)$ in the main group, and in the control group, it improved only by $7.6 \%$. Thus, a significant positive dynamic was noted for the psychophysiological parameters of athletes when using the device of fractal optical stimulation.

\section{The Motor Tests}

The results of the motor tests were unexpected. After the photo-stimulation, when performing the test with target number 1 , the number of strokes in the main group did not change $(0 \%)$, while in the control group the accuracy by $6.8 \%$ deteriorated following the rest pause. When performing the test with target number 2 , the number of strokes after a short rest significantly $(\mathrm{p}<0.05)$ increased in both groups/ it changes by $13 \%$ in the main group and by $9.6 \%$ - in the control group. 


\section{Pulsometry}

In the test of pulsometry, the heart rate was found decreased by $14.7 \%$ in the main group and $15.1 \%$ - in the control group. A practically equal improvement in the indices shows that the short-term fractal stimulation affects insignificantly for vegetative functions.

\section{Discussion}

Analysis of the link between internal and external training loads and the recovery-stress state is essential in sport practice for avoiding negative adaptations in high-performance sports [18-20]. This issue is especially important considering that in high-performance sports the recovery-stress state depends on the individual ability of the athlete to recover from the high physical and psychological loads [21-23]. In addition to defining the individual relationship of the training load and recoverystress state for the subject, it is necessary to develop new approaches to individual reduction of the period of recovery after intensive training and highly stressful activity. A theory linking the development and maintenance of the health structure and activity of the brain with the fractal complexity of visual and other environmental signals affecting a person during his life is grounded in 2015 [8]. From the theory, it follows that sensory stimulation of a person with low-intensity stimuli of fractal dynamics can be promising for improving and quickly restoring cognitive activity and human adaptive capabilities. We proposed that the using of fractal stimulation can be a prospective method of brain training in healthy individuals to better recovery after stressful situations and psycho-emotional overloads [9].

In this pilot study, we first estimated the impact of fractal optical stimulation for enhancing and restoring the physical and mental performance of table tennis athletes. The results of the study demonstrate that low-intensity stimulation with complex-structured optical signals positively influences the psychophysiological parameters characterizing the physical and mental performance of table tennis athletes. Brain's training with the short-term fractal stimulation improved the SVMR and CFF values significantly. This effect was much more essential compared to a rest impact in the control group. It suggests that for a complete recovery of time of the SVMR, it is not enough of the quiet rest for 10 minutes. It seems reasonable that the short break between training can be more productive if to increase the rest time or use methods increasing its efficacy. The observed an interesting fact of a significant decrease in the time of SVMR, possibly, will be useful for the planning of training and rest of athletes to provide better results. This phenomenon of the significant SVMR improvement after the short-time fractal photo-stimulation may be associated with an increase in the mobility of nervous processes in the cortical regions of the visual system. This proposition is also confirmed by an analysis of the changes in CFFs in the control and main groups. The lability of visual pathways restored after exercise stress more efficiently if the brain's training is applied with fractal optical stimulation than in regular rest for both eyes. In our experiment, this positive effect of fractal stimulation was more pronounced for the left eye.

The fractal stimulation also had the several times more prominent impact to the parameters of contact tremorometry than the ordinary rest. Thus, in the main group, when using the brain training device, a significantly favorable dynamics was noted for the studied psychophysiological parameters of athletes. The results of the motor tests were unexpected. Although the photo-stimulation did not change the efficiency of motor test with target number 1 , in the control group, the data were even less satisfactory. These data indicate, perhaps, the objective inexpediency (doubtful utility) of short breaks in physical training that may give a negative result instead of sporting success. In any case, fractal stimulation has shown the possibility to level out these negative influences. Measurements of heart rate showed that the fractal stimulation insignificantly impacts vegetative functions after the single 10-minute séance.

\section{Conclusion}

The stimulation with low-intensity complex-structured optical signals positively influences the psychophysiological parameters characterizing the physical and mental performance of table tennis athletes.

A single 10-minute seance of fractal stimulation during the rest showed the improvement of the rate of SVMR, the frequency and duration of the touch in contact tremorometry, and increased the CFF value for both eyes, indicating the increase in the lability of the visual analyzer. After an application of the fractal photo-stimulation, there was an improvement of accuracy in the performance of backhand stroke, and there was a stable technique of forehand stroke. The decrease in heart rate during rest period did not differ when using the fractal stimulation and without it. Preliminary results indicate that fractal optical stimulation has a positive effect on the physical and mental performance of athletes, but no effect on the rate of recovery of heart rate with short rest. To further study of useful effects of complex-structured visual stimuli, investigations should include the 2-3-weeks course of the training of the brain with the fractal stimulator in different situations, including pre-start training procedure of athletes, regular training, and rehabilitation after heavy loads.

\section{References}

1. Voskresenskaya EV, Melnik EV, Kukhtova NV (2015) Psychology of fear and anxiety in sports activities (theory and practice): Methodical recommendations. Vitebsk, Russian Federation: VSU named after P.M. Masherov p. 53.

2. Barchukova GV, Rodionov AV (2010) Influence of the mental state on the effectiveness of the competitive activity of qualified players in table tennis. Theory and practice of physical culture 7: 68-70.

3. Kurimay D, Pope-Rhodius A, Kondric M (2017) The Relationship Between Stress and Coping in Table Tennis. Journal of Human Kinetics (Racket Sports) 55: 75-81. 
4. Larcombe Ben (2015) Mental Training for Table Tennis.

5. Priestley S, Larcombe B (2015) Expert in a year: The ultimate table tennis challenge. CreateSpace Independent Publishing Platform, pp. 144

6. Barlow JS (1960) Rhythmic activity induced by photic stimulation in relation to intrinsical activity of the brain in man. Electroencephalogr Clin Neurophysiol 12(2): 317-326.

7. Williams J, Ramaswamy D, Oulhaj A (2006) $10 \mathrm{~Hz}$ flicker improves recognition memory in older people. BMC Neurosci 7: 21.

8. Zueva MV (2015) Fractality of sensations and the brain health: the theory linking neurodegenerative disorder with distortion of spatial and temporal scale-invariance and fractal complexity of the visible world. Front Aging Neurosci 7:135.

9. Zueva MV (2018) Technologies of Nonlinear Stimulation: Role in the Treatment of Diseases of the Brain and the Potential Applications in Healthy Individuals. Human Physiology 44(3): 289-299.

10. Goldberger AL, Amaral LAN, Hausdor LM, Ivanov PCh, Peng CK, et al. (2002) Fractal dynamics in physiology: Alterations with disease and aging. Proc Nat Acad Sci 99: 2466-2472.

11. Manor B, Lipsitz LA (2013) Physiologic complexity and aging: Implications for physical function and rehabilitation. Prog Neuro sychopharmacol Biol Psychiatry 45: 287-293.

12. Weerda R, Muehlhan M, Wolf OT, Thiel CM (2010) Effects of Acute Psychosocial Stress on Working Memory Related Brain Activity in Men Hum Brain Mapp 31(9): 1418-1429.

13. Joels M, Pu Z, Wiegert O, Oitzl MS, Krugers HJ (2006) Learning under stress: How does it work? Trends Cogn Sci 10(4): 152-158.

14. Schwabe L, Joels M, Roozendaal B, Wolf OT, Oitzl MS (2012) Stress effects on memory: An update and integration. Neurosci Biobehav Rev 36(7): 1740-1749.
15.Vogel S, Schwabe L (2016) Learning and memory under stress: implications for the classroom. npj Science of Learning, Article 16011.

16. De la Torre-Luque A, Bornas X, Balle M, Fiol-Veny A (2016) Complexity and nonlinear biomarkers in emotional disorders: A meta-analytic study. Neurosci Biobehav Rev 68: 410-422.

17.Zueva MV (2013) Dynamic fractal flickering as a tool in research of non-linear dynamics of the evoked activity of a visual system and the possible basis for new diagnostics and treatment of neurodegenerative diseases of the retina and brain. WASJ 27(4): 462-468.

18.Smith DJ (2003) A framework for understanding the training process leading to elite performance. Sports Med 33(15): 1103-1126.

19.Lambert MI, Mujika I (2013) Overtraining prevention. In: Recovery for Performance in Sport. Champaign, IL, United States: Human Kinetics Publishers p. 23-28.

20. Kellmann M, Bertollo M, Bosquet L, Brink MS, Coutts A, et al. (2018) Recovery and performance in sport: consensus statement. Int J Sports Physiol Perform 13(2): 240-245.

21. Morgan WP, Brown DR, Raglin JS, O Connor PJ, Ellickson KA (1987) Psychological monitoring of overtraining and staleness. Br J Sports Med 21(3): 107-114.

22.Nassi A, Ferrauti A, Meyer T, Pfeiffer M, Kellmann M (2017) Development of two short measures for recovery and stress in sport. Eur J Sport Sci 17(7): 894-903.

23. Collette R, Kellmann M, Ferrauti A, Meyer T, Pfeiffer M (2018) Relation Between Training Load and Recovery-Stress State in High-Performance Swimming. Front Physiol p. 9.

Your next submission with Juniper Publishers will reach you the below assets

- Quality Editorial service

- Swift Peer Review

- Reprints availability

- E-prints Service

- Manuscript Podcast for convenient understanding

- Global attainment for your research

- Manuscript accessibility in different formats ( Pdf, E-pub, Full Text, Audio)

- Unceasing customer service

Track the below URL for one-step submission https://juniperpublishers.com/online-submission.php 